\title{
Lentivirus-mediated estrogen receptor $\alpha$ overexpression in the central nervous system ameliorates experimental autoimmune encephalomyelitis in mice
}

\author{
XIAO HU ${ }^{1,2}$ and XINYUE QIN ${ }^{1}$ \\ ${ }^{1}$ Department of Neurology, The First Affiliated Hospital of Chongqing Medical University, Chongqing 400016; \\ ${ }^{2}$ Department of Neurology, Guizhou Provincial People's Hospital, Guizhou 550002, P.R. China
}

Received January 25, 2013; Accepted March 5, 2013

DOI: $10.3892 /$ ijmm.2013.1306

\begin{abstract}
Multiple sclerosis (MS) is an autoimmune disease characterized by inflammatory cell infiltration of the central nervous system (CNS) and multifocal demyelination. Clinical data and clinical indicators demonstrate that estrogen improves the relapse-remittance of MS patients. This study aimed to investigate the anti-inflammatory effects and the underlying mechanism(s) of action of estrogen and estrogen receptor $\alpha$ $(E R \alpha)$ in an experimental autoimmune encephalomyelitis (EAE) mouse model of MS. An ER $\alpha$ recombinant lentivirus was constructed. Mouse neurons were cultured in serum-free culture medium, and $\mathrm{ER} \alpha$ recombinant lentivirus with a multiplicity of infection (MOI) of 5 was used to infect the neurons. Furthermore, neuronal ER $\alpha$ mRNA and protein expression were detected using real-time quantitative PCR and western blot analysis. We sterotaxically injected ER $\alpha$ recombinant lentivirus into the lateral ventricle of mouse brains, and successfully identified infected neurons using Flag immunofluorescence staining to determine the optimal dose. A total of 75 C57BL/6 mice were ovariectomized. After 2 weeks, EAE was induced with myelin oligodendrocyte glycoprotein (MOG) $35-55$ peptide. The EAE mice were divided into 5 groups: the estrogen group (treatment with estradiol), the ER $\alpha$ agonist group (treatment with raloxifene), the $\mathrm{ER} \alpha$ recombinant lentivirus group (ER $\alpha$ group, treatment with $\mathrm{ER} \alpha$ recombinant lentivirus), the empty virus group and the normal saline (NS) group; clinical symptoms and body weight were compared among the groups. We assessed EAE-related parameters, detected pathological changes with immunohistochemistry and quantified the expression of myelin basic protein (MBP), matrix metalloproteinase-9 (MMP-9), and a subset of EAE-related cytokines using enzyme-linked immu-
\end{abstract}

Correspondence to: Dr Xinyue Qin, Department of Neurology, The First Affiliated Hospital of Chongqing Medical University, 1 Youyi Road, Yuzhong, Chongqing 400016, P.R. China

E-mail: qinxinyue12012@126.com

Key words: multiple sclerosis, estrogen, estrogen receptor $\alpha$, inflammatory response, recombinant lentivirus nosorbent assay (ELISA). We successfully constructed an ER $\alpha$ recombinant lentivirus. C57BL/6 mouse neurons can survive in culture for at least 8 weeks. During that period, the recombinant lentivirus was able to infect the neurons, while sustaining green fluorescence protein (GFP) expression. $\mathrm{ER} \alpha$ recombinant lentivirus also infected the neurons at a MOI of 5. The ER $\alpha$ mRNA and protein expression levels were higher in the infected neurons compared to the uninfected ones. We successfully infected the CNS of C57BL/6 mice by stereotaxically injecting $\mathrm{ER} \alpha$ recombinant lentivirus into the lateral ventricle of the mouse brains and induced EAE. The lentivirus-mediated overexpression of ER $\alpha$ reduced the incidence of EAE, ameliorated the clinical symptoms, inhibited inflammatory cell CNS infiltration, and reduced nerve fiber demyelination. MMP-9, tumor necrosis factor- $\alpha$ (TNF- $\alpha$ ), interferon- $\gamma$ (IFN- $\gamma)$, interleukin (IL)-17 and IL-23 expression levels were decreased, while those of MBP and IL-4 were increased. These data demonstrate that it is possible to induce the overexpression of ER $\alpha$ using a recombinant lentivirus, and that this novel intervention ameliorates EAE in a mouse model. Mechanistically, estrogen and ER $\alpha$ inhibit inflammatory responses, and $\mathrm{ER} \alpha$ alleviates damage to the myelin sheath. Collectively, our findings support the potential use of $\mathrm{ER} \alpha$ as a therapeutic target for the treatment of MS.

\section{Introduction}

Experimental autoimmune encephalomyelitis (EAE) is a widely used model of multiple sclerosis (MS). Both are characterized by immune cell infiltration from small blood vessels into the central nervous system (CNS) and subsequent $\mathrm{CD} 4^{+} \mathrm{T}$ cell-mediated axonal demyelination (1). MS is a chronic CNS inflammatory disease that exhibits an earlier onset and higher incidence rate in females than males (2). MS severity and relapse frequency decrease significantly during late pregnancy (3). However, the disease usually shows increased relapse frequency and severity during the postpartum period (4), and this is associated with reduced estrogen levels (5). Clinical studies have indicated that oral estrogen administration exerts immunoregulatory effects and reduces the number and size of gadolinium-enhancing lesions in relapsing-remitting MS patients, suggesting that estrogen is an effective drug for MS therapy $(6,7)$. Certain studies have reported that estriol exerts anti-inflammatory 
effects, such as inhibiting Th1 and Th17 cell priming $(8,9)$, regulatory B cells (10) and T cells (11), as well as inhibiting matrix metalloproteinase-9 (MMP-9) activity (12). Other studies have demonstrated that estriol decreases gray matter atrophy (13) and reduces inappropriate excitatory synaptic transmission and other neuropathological hippocampal changes during EAE (14). It has been reported that chronic neuroinflammation and nuclear factor- $\mathrm{kB}$-dependent chemokine $\mathrm{C}-\mathrm{C}$-motif ligand (CCL)2 expression in reactive astrocytes can be inhibited by estriol (15). Estrogen also plays a protective role. A number of published studies have described in detail that different types of estrogen receptor (ER) signaling ameliorate EAE-induced damage $(9-11,16,17)$. Collectively, these reports, as well as others indicate that estrogen treatment exerts neuroprotective effects against EAE on the CNS. In this study, we expanded on this line of research and investigated the utility of inducing the overexpression of $\mathrm{ER} \alpha$ using a lentivirus.

The biological effects of estrogens are differentially mediated through ER $\alpha$ and ER $\beta$, and G protein-coupled ER30 (GPR30). Some studies have investigated the impact of ER $\beta$ signaling. Tiwari-Woodruff and Voskuhl found that the ER $\beta$ ligand had no effect at EAE onset, but promoted recovery (18). Du et al reported that ER $\beta$ ligand administration did not reduce overall CNS inflammation in EAE, but it did decrease the percentage of dendritic cells (DCs) (19). Other studies have reported a protective effect of GPR30 activation in EAE. Blasko et al suggested that during EAE, GPR30 indirectly mediates a decrease in proinflammatory cytokines, including interleukin (IL)-17 and interferon- $\gamma($ IFN- $\gamma)$ in immune cells (20). GPR30 plays a key role in the estrogen-dependent and vitamin D3-mediated protection in EAE, which could enhance IL-10 and IL-6 secretion by myelin oligodendrocyte glycoprotein (MOG) peptide-reactive splenocytes and promote CCL5, chemokine receptor (CCR)1, and CCR3 expression in spleen tissue (21). GPR30 membrane ER treatment has been shown to alter cytokine profiles and enhance the suppressive activity of $\mathrm{CD}^{+}{ }^{+} \mathrm{Foxp}^{+} \mathrm{T}$ cells through a GPR30 and programmed death-1 (PD-1)-dependent mechanism (16). ER $\alpha$ also plays an important role in EAE. Firstly, estrogens exert protective effects during EAE through ER $\alpha$ by inhibiting the recruitment of blood-derived inflammatory cells into the CNS (22). Secondly, certain studies have reported estrogen-mediated protection against EAE in regulatory B cells and the mediation of MMP-9 activity through ER $\alpha(10,23)$. Thirdly, Lelu et al demonstrated that ER $\alpha$ expression is critical in hematopoietic, but not endothelial cells; it mediates the estrogen inhibitory effect on Th1 and Th17 cell priming, which protects against EAE (8). Finally, reactive astrocytes are a target of the inhibitory action of nuclear ER $\alpha$ on chemokine expression; this observation suggests that targeting astrocytic nuclear factor- $\mathrm{\kappa} B$ may be a useful therapeutic goal $(15,24)$. Although exclusively investigated, the exact role of ER $\alpha$ in EAE requires further study.

Evidence indicates that therapeutic genes expressed in lentiviral vectors are applicable for the treatment of many types of neurological disorders, due to the characteristics of the sustained expression of targeted genes and no obvious unwanted side-effects of lentivirus vectors per se (25). Foster et al found that restoring ER $\alpha$ expression via lentiviral hippocampal delivery improved the hippocampal response to estrogen in $E R \alpha^{-/}$mice (26), suggesting that the presence of $E R \alpha$ in the CNS is crucial for estrogen function and that a lentiviral delivery system is a viable way of manipulating CNS gene expression. In this study, we established an experimental model to identify and characterize the effect and mechanism of action of nuclear ER in EAE. We induced the overexpression of ER $\alpha$ in the CNS by injecting recombinant lentivirus into the lateral cerebral ventricle, to investigate the effect and mechanism of action of ER $\alpha$ in the CNS in EAE mice; estradiol and the ER $\alpha$ agonist, raloxifene, were used as the positive controls. Our results demonstrate that the lentivirus-mediated delivery of an $\mathrm{ER} \alpha$ gene is a viable method of increasing CNS-targeted protein expression and is effective in ameliorating the symptoms of EAE in a mouse model of MS.

\section{Materials and methods}

Animals. We purchased 75 4-week-old female C57BL/6 mice weighing 19-22 g from the Experimental Animal Center of Chongqing Medical University [Certificate of Conformity: SCXK (Chongqing) 2007-000341]. All mice were handled in accordance with the requirements of the Chongqing University Medical School Laboratory Animal Ethics Committee.

Reagents. The plasmid pMD19-ER $\alpha$, 293T (human embryonic kidney) cells, and Escherichia coli DH5a were obtained from the Central Laboratory of Guizhou People's Hospital, Guizhou, China. The lentiviral vector, LV-GFP-Flag [with green fluorescence protein (GFP) and Flag tag] was purchased from Shanghai GeneChem Corp. (Shanghai, China). The helper plasmids, pHelper 1.0 and pHelper 2.0, Lipofectamine 2000 and TRIzol were purchased from Invitrogen (Carlsbad,CA, USA). Raloxifene hydrochloride tablets (easy Witte ${ }^{\mathrm{TM}}$ ) were purchased from Eli Lilly (Indianapolis, IN, USA). Estradiol valerate (Progynova ${ }^{\mathrm{TM}}$ ) was purchased from Schering AG (Berlin-Wedding, Germany). MOG 35-55 peptide (MEVGWYRSPFSRVVHLYRNGK, purity $>97 \%$ ) was purchased from the Xi'an AP Peptide Synthesis Company (Xi'an, China). Pertussis toxin was a gift from the Chengdu Institute of Biological Products in China. Bacillus Calmette-Guerin (BCG) vaccine was purchased from Chinese Pharmaceutical and Biological Products (Chengdu, China). Trypsin was purchased from Ameresco (Solon, $\mathrm{OH}$, USA). Dulbecco's modified Eagle's medium (DMEM)/F12, D-Hank's solution, and protein assay kits were purchased from HyClone (Logan, UT, USA). Fetal bovine serum and B-27 were purchased from Gibco (Carlsbad). Mouse anti-ER $\alpha$ monoclonal antibody was purchased from Lifespan Biosciences (Seattle, WA, USA). Mouse monoclonal antibody to glyceraldehyde 3-phosphate dehydrogenase (GAPDH) and goat anti-mouse IgG were purchased from Santa Cruz Biotechnology (Santa Cruz, CA, USA). Rabbit anti-matrix MMP-9 polyclonal antibody and fluorescein isothiocynate (FITC)-labeled goat anti-rabbit IgG were purchased from Beijing Boao Sen Corp. (Beijing, China). Luxol fast blue (LFB), cresyl fast violet and complete Freund's adjuvant were obtained from Sigma-Aldrich (St. Louis, MO, USA). The BioRT reverse transcription-polymerase chain reaction (RT-PCR) kit was purchased from Bio Flux Corp. (Tokyo, Japan). The SYBR Master Mixture kit was obtained from Takara (Dalian, China). Mouse anti-myelin basic protein (MBP) antibody was purchased from Abcam (Cambridge, UK). Polyvinylidene fluoride (PVDF) membranes were obtained from 
Bio-Rad (Hercules, CA, USA). The ACS 180E2 chemiluminescent immunoassay reagent kit was obtained from Bayer Corp. (Pittsburgh, PA, USA). Mouse TNF- $\alpha$, IFN- $\gamma$, IL-4, IL-17, IL-23 and MMP-9 enzyme-linked immunosorbent assay (ELISA) kits were purchased from R\&D Systems (Minneapolis, MN, USA). An enhanced chemiluminescence (ECL)-Plus kit was obtained from Amersham (Piscataway, NJ, USA). Primers were designed and synthesized by Sangon (Shanghai, China).

Primary neuronal cell culture. Cell culture was conducted as previously described (27). C57BL/6 mice were sacrificed within $24 \mathrm{~h}$ of birth, and their cortical tissues were dissected. A single cell suspension was obtained following trypsinization, and these neuronal cells were seeded at a density of $1 \times 10^{5}$ cells/well in 6 -well plates and $1 \times 10^{7}$ cells $/ 15 \mathrm{ml}$ flask and cultured in an incubator operating at $37^{\circ} \mathrm{C}$ under $5 \% \mathrm{CO}_{2}$. After $24 \mathrm{~h}$, the basal medium was replaced with a serum-free medium (DMEM/F12 medium supplemented with $1 \%$ growth factor B-27, $10^{4}$ units $/ \mathrm{ml}$ penicillin and $10 \mathrm{mg} / \mathrm{ml}$ streptomycin). Half of the serum-free medium was replaced with fresh medium every 3 days.

Determination of raloxifene concentration. The blood drug concentration of raloxifene was determined as follows: blood samples were collected from the EAE mice. A precise volume of $1 \mathrm{ml}$ of plasma sample was transferred to centrifuge tubes. A total of $50 \mu \mathrm{l}$ of internal reference solution was then added and mixed evenly. Approximately $200 \mu \mathrm{l}$ of $\mathrm{NaOH}$ solution $(1 \mathrm{mmol} / \mathrm{l})$ was added into the mixed solution, rotated for $20 \mathrm{sec}$, followed by the addition of $5 \mathrm{ml}$ of hexane-butanol $(98: 2, \mathrm{v} / \mathrm{v})$, rotation for $3 \mathrm{~min}$ and centrifugation at 4,000 rpm for $10 \mathrm{~min}$. A precise volume of $4 \mathrm{ml}$ of organic phase was collected and transferred to another centrifuge tube, and then blow-dried with nitrogen flow in a water bath at $40^{\circ} \mathrm{C}$. The residue was dissolved in $200 \mu \mathrm{l}$ of mobile phase and centrifuged at $16,000 \mathrm{rpm}$ for 2 min. The supernatant was collected and transferred to the small bottle in the automated chemiluminescent immunoassay analyzer, and vertically illuminated under an ultraviolet lamp at a wavelength of $254 \mathrm{~nm}$ for $10 \mathrm{~min}$. A precise volume of $10 \mu \mathrm{l}$ of the supernatant was collected for determination.

ER $\alpha$ recombinant lentivirus construction and transfection. Lentiviral transfection was performed as described in a previous study (28). Briefly, a PCR-amplified gene fragment encoding ER $\alpha$ was cut using the restriction enzymes, AgeI/ NheI, and cloned into the LV-GFP-Flag vector. The plasmid sequences were confirmed by sequencing. The ER $\alpha$ recombinant vector or the empty viral vector was co-transfected with the pHelper 1.0 and pHelper 2.0 helper plasmids into 293T cells using Lipofectamine 2000. The lentivirus-containing supernatant was collected, centrifuged and filtered. The titer of ER $\alpha$ recombinant lentivirus was determined using real-time quantitative PCR. Neuronal cells cultured for 7 days were infected with $\mathrm{ER} \alpha$ recombinant lentivirus at a multiplicity of infection (MOI) of 5. GFP expression in the infected cells was observed daily under an inverted fluorescence microscope. Five days after infection, ER $\alpha$ recombinant lentivirus-infected and -uninfected neuronal cells were collected, and total RNA and protein were extracted. ER $\alpha$ expression was examined by RT-PCR and western blot analysis. The primer sequences are shown in Table I.
Ovariectomy and EAE animal model preparation. A total of 75 female C57BL/6 mice were anesthetized and underwent bilateral tubal ligation and ovariectomy. Two weeks later, an mouse model of MS was established. MOG 35-55 peptide was diluted with $0.01 \mathrm{~mol} / \mathrm{l}$ phosphate-buffered saline (PBS) to $300 \mu \mathrm{g} / \mathrm{ml}$, combined with the same amount of complete Freund's adjuvant (final concentration of BCG of $10 \mathrm{mg} / \mathrm{ml}$ ) and mixed with a glass syringe to form an antigen emulsion. EAE was induced with a subcutaneous injection of $0.2 \mathrm{ml}$ antigen emulsion at the back, neck, armpit and groin at 0 and 7 days post-immunization, and intraperitoneal injections of $0.4 \mathrm{mg}$ pertussis toxin were administered at 0 and 2 days post-immunization. EAE mice were divided into 5 groups $(n=17$ per group): the estrogen, $\mathrm{ER} \alpha$ agonist, $\mathrm{ER} \alpha$ recombinant lentivirus, empty virus vector and normal saline (NS) group. From days 7 to 30 following immunization, the estrogen and ER $\alpha$ agonist groups were subcutaneously treated with a saline suspension of estradiol valerate (0.04 mg/kg/day) (29) and a raloxifene saline suspension ( $2 \mathrm{mg} /$ $\mathrm{kg} /$ day) (30), respectively. On the day of immunization, mice in the ER $\alpha$, empty virus and NS group were anesthetized with sodium pentobarbital $(40 \mathrm{mg} / \mathrm{kg})$ and injected with $20 \mu \mathrm{l} \mathrm{ER} \alpha$ lentivirus, empty virus, or saline, respectively. Injections were made into the lateral cerebral ventricle located $2.0 \mathrm{~mm}$ posterior and $1.5 \mathrm{~mm}$ lateral to the bregma at a depth of $2.5 \mathrm{~mm}$ using stereotaxic techniques. Animals in each group were euthanized at 5,10, 20 and 30 days post-injection, and the spinal cords and brain tissue were harvested for analysis. Hematoxylin and eosin (H\&E) staining was performed to assess the inflammatory response in the brain and spinal cord tissues of normal mice following injection with $\mathrm{ER} \alpha$ recombinant lentivirus.

To examine the effects of raloxifene and estradiol valerate on EAE induction and severity, mice received treatment or placebo by subcutaneous injection from days 10 to 30 following immunization.

Determination of estradiol concentraion. Blood samples were collected from the EAE mice and dissolved at room temperature, mixed evenly, and centrifuged at 4,000 rpm for $5 \mathrm{~min}$. Approximately $250 \mu \mathrm{l}$ of serum samples were collected and transferred to tubes for subsequent determination. The cleaning and filling procedures of the fully automated chemiluminescent immunoassay analyzer were performed. The luminous agent and solid-phase secondary antibody were added according to the instructions provided with the ACS 180E2 chemiluminescent immunoassay reagent kit, and the mixed procedure was executed for $20 \mathrm{~min}$. The calibration solution, control solution and antibody were added into the sample plates, and the calibration and control programs were set up on a computer. The blood drug concentration of estradiol was automatically determined using the immunoassay analyzer.

EAE evaluation. Body weight and clinical scores were recorded daily. We employed a standard scale used for EAE model evaluation (31) that consists of: 1 , paresis of the tail; 2 , paresis of a hind limb; 3, paralysis of a hind limb; 4, paralysis of a forelimb; and 5, a moribund state or death.

Pathological analysis. Five EAE mice in each group were sacrificed at 16 days post-immunization (dpi) (acute phase), 5 mice were sacrificed at $23 \mathrm{dpi}$ (remission phase), and 5 mice 
Table I. Primer sequences.

\begin{tabular}{|c|c|c|}
\hline Primer name & & Primer sequence $\left(5^{\prime} \rightarrow 3^{\prime}\right)$ \\
\hline ER $\alpha$ coding region & $\begin{array}{l}\text { Forward } \\
\text { Reverse }\end{array}$ & $\begin{array}{l}\text { GAGGATCCCCGGGTACCGGTCGCCACCATGACCATGACCCTTCACAC } \\
\text { TCATCCTTGTAGTCGCTAGCGATCGTGTTGGGGAAGC }\end{array}$ \\
\hline $\mathrm{ER} \alpha$ lentivirus vector & $\begin{array}{l}\text { Forward } \\
\text { Reverse }\end{array}$ & $\begin{array}{l}\text { GATCCACCTGATGGCCAAAG } \\
\text { AGCGTAAAAGGAGCAACATAG }\end{array}$ \\
\hline $\mathrm{ER} \alpha$ & $\begin{array}{l}\text { Forward } \\
\text { Reverse }\end{array}$ & $\begin{array}{l}\text { AATTCCTGGTGTTGTCG } \\
\text { AAGGTCCGCTGGATTGAG }\end{array}$ \\
\hline$\beta$-actin & $\begin{array}{l}\text { Forward } \\
\text { Reverse }\end{array}$ & $\begin{array}{l}\text { GTGGACATCCGCAAAGAC } \\
\text { AAAGGGTGTAACGCAACTA }\end{array}$ \\
\hline MMP-9 & $\begin{array}{l}\text { Forward } \\
\text { Reverse }\end{array}$ & $\begin{array}{l}\text { GCCCTGGAACTCACACGACA } \\
\text { TTGGAAA CTCACACGCCAGAAG }\end{array}$ \\
\hline TNF- $\alpha$ & $\begin{array}{l}\text { Forward } \\
\text { Reverse }\end{array}$ & $\begin{array}{l}\text { GCCACAAGCAGGAATGAGAAG } \\
\text { GCCACAAG CAGGAATGAGAAG }\end{array}$ \\
\hline IFN- $\gamma$ & $\begin{array}{l}\text { Forward } \\
\text { Reverse }\end{array}$ & $\begin{array}{l}\text { TTTGCAGCTCTTCCTCAT } \\
\text { TGCCAGTTCCTCCAGATA }\end{array}$ \\
\hline IL-4 & $\begin{array}{l}\text { Forward } \\
\text { Reverse }\end{array}$ & $\begin{array}{l}\text { TCTCGAATGTACCAGGAGCCATATC } \\
\text { AGCACCTTGGAAGCCCTACAGA }\end{array}$ \\
\hline IL-23 & $\begin{array}{l}\text { Forward } \\
\text { Reverse }\end{array}$ & $\begin{array}{l}\text { ACATGCACCAGCGGGACATA } \\
\text { CTTTGAAGATGTCAGAGTCAAGCAG }\end{array}$ \\
\hline IL-17 & $\begin{array}{l}\text { Forward } \\
\text { Reverse }\end{array}$ & $\begin{array}{l}\text { ACGCGCAAACATGAGTCCAG } \\
\text { AGGCTCAGCAGCAGCAACAG }\end{array}$ \\
\hline
\end{tabular}

ER $\alpha$, estrogen receptor $\alpha$; MMP-9, matrix metalloproteinase-9; TNF- $\alpha$, tumor necrosis factor- $\alpha$; IFN- $\gamma$, interferon- $\gamma$; IL, interleukin .

were sacrificed at 30 dpi (chronic phase). The spinal cords of the acute phase mice were fixed in $4 \%$ paraformaldehyde for $24 \mathrm{~h}$, embedded in paraffin, and cut into $5 \mu \mathrm{m}$-thick sections for $\mathrm{H} \& \mathrm{E}$ staining and LFB-H\&E staining as previously described (27). The scores of the inflammatory responses were evaluated on a 5-point scale as described previously (32): 0 , no infiltration of inflammatory cells; 1 , infiltration only into the subarachnoid space; 2 , mild infiltration into the brain parenchyma; 3 , moderate infiltration into the brain parenchyma; and 4, severe and diffuse inflammatory cell infiltration into the brain parenchyma. Nerve demyelination scores were evaluated on a 4-point scale as follows: 0 , no demyelination; 1 , mild demyelination; 2 , moderate demyelination; and 3 , severe demyelination.

MMP-9 immunofluorescence staining. Paraffin-embedded tissues were cut into $6 \mu \mathrm{m}$-thick sections, dewaxed, rehydrated, subjected to antigen retrieval and permeabilized with $0.1 \%$ Triton X-100. The sections were blocked in pre-immune serum blocking solution (1:10) for $20 \mathrm{~min}$, incubated with an anti-MMP-9 antibody (1:100), followed by incubation with a FITC-labeled secondary antibody (1:100). The sections were observed using an Axiovert 200M fluorescence microscope (Zeiss, Jena, Germany). Five random and non-overlapping fields were collected from each section, and the integral optical density (IOD) values were calculated and averaged with the microscope's image analysis system.
Real-time quantitative PCR. Total brain RNA was extracted with TRIzol and reverse transcribed to cDNA using a BioRT reverse transcription kit. Real-time quantitative PCR was performed using an SYBR Master Mixture kit according to the manufacturer's instructions. An RT quality control and a PCR negative control were included, and $\beta$-actin was used as an internal control. Relative gene expression levels were calculated according to the cycle threshold $(\mathrm{Ct})$ values of target genes relative to the internal control gene. The primers are shown in Table I.

ELISA. Brain tissues were washed with ice-cold PBS, dried on filter paper, diluted in saline to form a $10 \%$ brain tissue homogenate, and centrifuged at $2,800 \mathrm{x}$ g for $10 \mathrm{~min}$ at $4^{\circ} \mathrm{C}$. TNF- $\alpha$, IFN- $\gamma$, MMP-9, IL-4, IL-17 and IL-23 expression levels in the supernatants were detected using a double antibody sandwich ELISA kit according to the manufacturer's instructions.

Western blot analysis. Cell lysates were equally loaded, and the proteins were separated by $10 \%$ sodium dodecyl sulfate-polyacrylamide gel electrophoresis (SDS-PAGE). The separated proteins were transferred onto PVDF membranes at $4^{\circ} \mathrm{C}, 400 \mathrm{~mA}$ for $120 \mathrm{~min}$. Membranes were blocked in Tris-buffered saline buffer containing Tween-20 (TBST) and 5\% skimmed milk for $1 \mathrm{~h}$ and incubated with mouse anti-ER $\alpha$ monoclonal antibody (1:500), mouse anti-MBP antibody $(1: 1,000)$, or mouse anti-GAPDH monoclonal antibody 
A

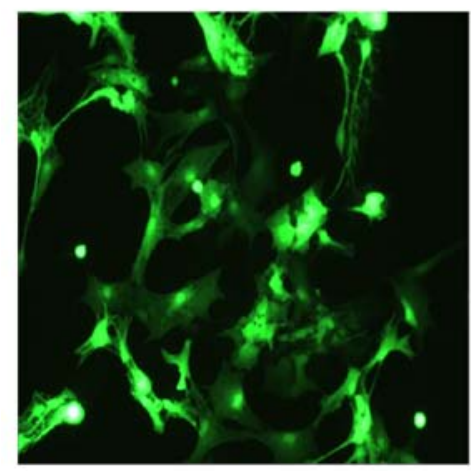

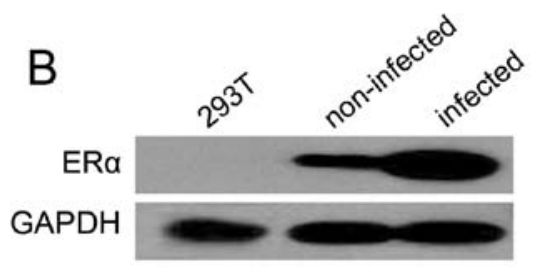

C

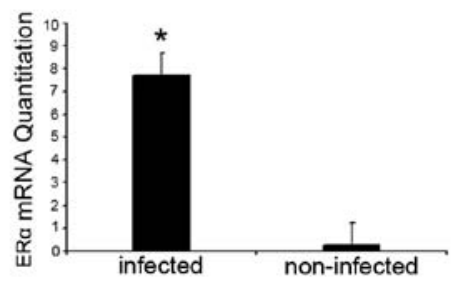

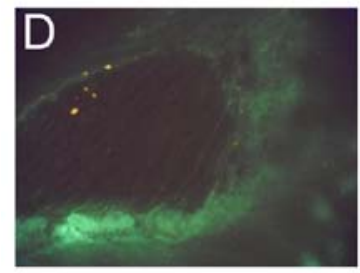
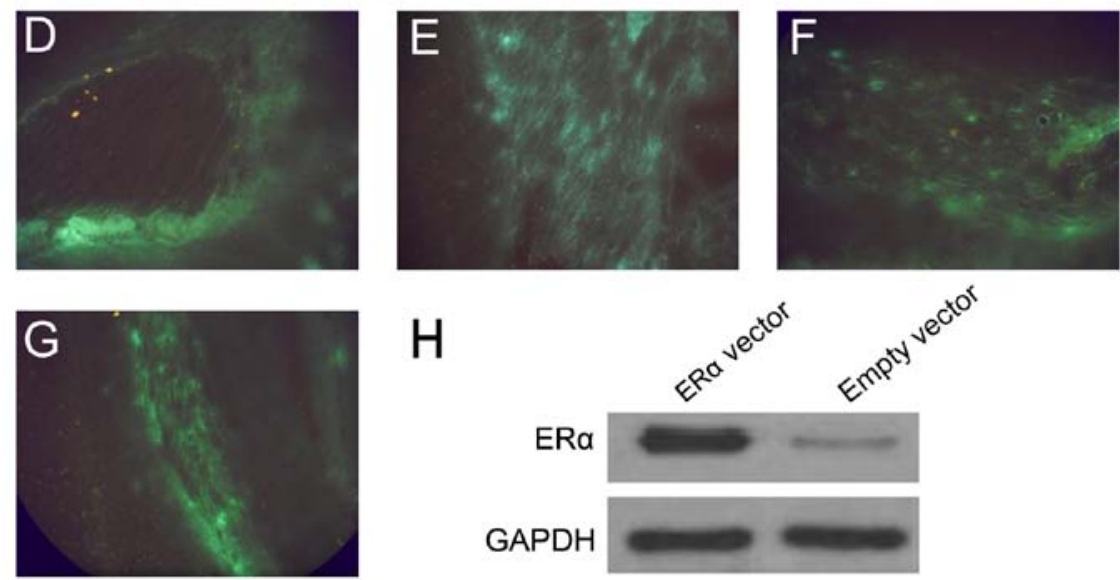

Figure 1. ER $\alpha$ recombinant lentivirus transfection. (A) Green fluorescence protein (GFP) expression in neuronal cells following estrogen receptor (ER) $\alpha$ lentivirus (MOI of 5) infection for $72 \mathrm{~h}$ (x400). (B) ER $\alpha$ protein expression assessed by western blot analysis. The relative amount of ER $\alpha$ protein in the control cells was $0.241 \pm 0.053$ and $1.032 \pm 0.16$ in the infected cells $(\mathrm{P}<0.01, \mathrm{n}=5)$. $(\mathrm{C})$ The ER $\alpha \mathrm{mRNA}$ expression level in infected neuronal cells increased $7462 \pm 1417$-fold compared to the control cells ( $\mathrm{P}<0.001, \mathrm{n}=5$ ). (D-G) GFP expression in (D) hippocampus, $(\mathrm{E})$ region around the lateral ventricle, $(\mathrm{F})$ brain parenchyma, and $(\mathrm{G})$ spinal cord. $(\mathrm{H})$ Western blot showing ER $\alpha$ expression in mouse brain homogenate following lentivirus administration. All experiments were performed in triplicate.

$(1: 2,500)$ at $4^{\circ} \mathrm{C}$ overnight. The following day, membranes were incubated with sheep anti-mouse $\operatorname{IgG}(1: 5,000)$ at room temperature for $1 \mathrm{~h}$, and the blots were visualized using an ECL-PLUS kit. GAPDH was used as an internal control. Relative protein expression levels are described as the band density of target proteins relative to GAPDH.

Statistical analysis. All experiments were performed at least in triplicate. Statistical analyses included one-way analysis of variance and Newman-Keuls multiple comparisons tests. The summarized data are presented as the means \pm standard deviation, and a P-value $<0.05$ was considered to indicate a statistically significant difference.

\section{Results}

ER $\alpha$ overexpression with recombinant lentivirus in vitro and in vivo. We achieved ER $\alpha$ overexpression with recombinant lentiviral transfection in vitro and in vivo. In the cultured neuronal cells, a sustained GFP expression was observed for at least 8 weeks (Fig. 1A) following infection with ER $\alpha$ recombinant lentivirus (titer of $2 \times 10^{8} \mathrm{TU} / \mathrm{ml}$; MOI of 5), suggesting that the lentiviral infection of the neuronal cells was effective and stable. Moreover, ER $\alpha$ mRNA and protein levels were significantly upregulated in the lentiviral-transfected neuronal cells (Fig. 1B and C). We also induced the overexpression of $\mathrm{ER} \alpha$ in EAE mice by injecting recombinant lentivirus into the lateral ventricle of the mouse brains. At 5, 10, 20 and 30 days post-injection, EAE mice receiving ER $\alpha$ recombinant lentivirus and the empty vector controls were sacrificed. We detected a strong GFP signal in the EAE mice that received $\mathrm{ER} \alpha$ recombinant lentivirus in several CNS regions, including the hippocampus (Fig. 1D), the region around the lateral ventricle (Fig. 1E), brain parenchyma (Fig. 1F) and spinal cord (Fig. 1G), suggesting the successful overexpression of $\mathrm{ER} \alpha$ in vivo. By 5 days post-injection, $\mathrm{ER} \alpha$ protein expression in the animals receiving $\mathrm{ER} \alpha$ recombinant lentivirus was increased relative to the controls $(\mathrm{Fig} .1 \mathrm{H})$, and this was maintained throughout the course of the experiment. H\&E staining showed that $\mathrm{ER} \alpha$ recombinant lentivirus injection did not induce inflammatory responses in the brain or spinal cord tissues of the normal mice.

ERa overexpression improves clinical signs of disease in EAE mice. The estrogen and $\mathrm{ER} \alpha$ agonist group received a subcutaneous injection containing saline suspensions of estradiol valerate $(0.04 \mathrm{mg} / \mathrm{kg} / \mathrm{day})$ and a raloxifene saline suspension ( $2 \mathrm{mg} / \mathrm{kg} /$ day), respectively. The doses were selected to produce 

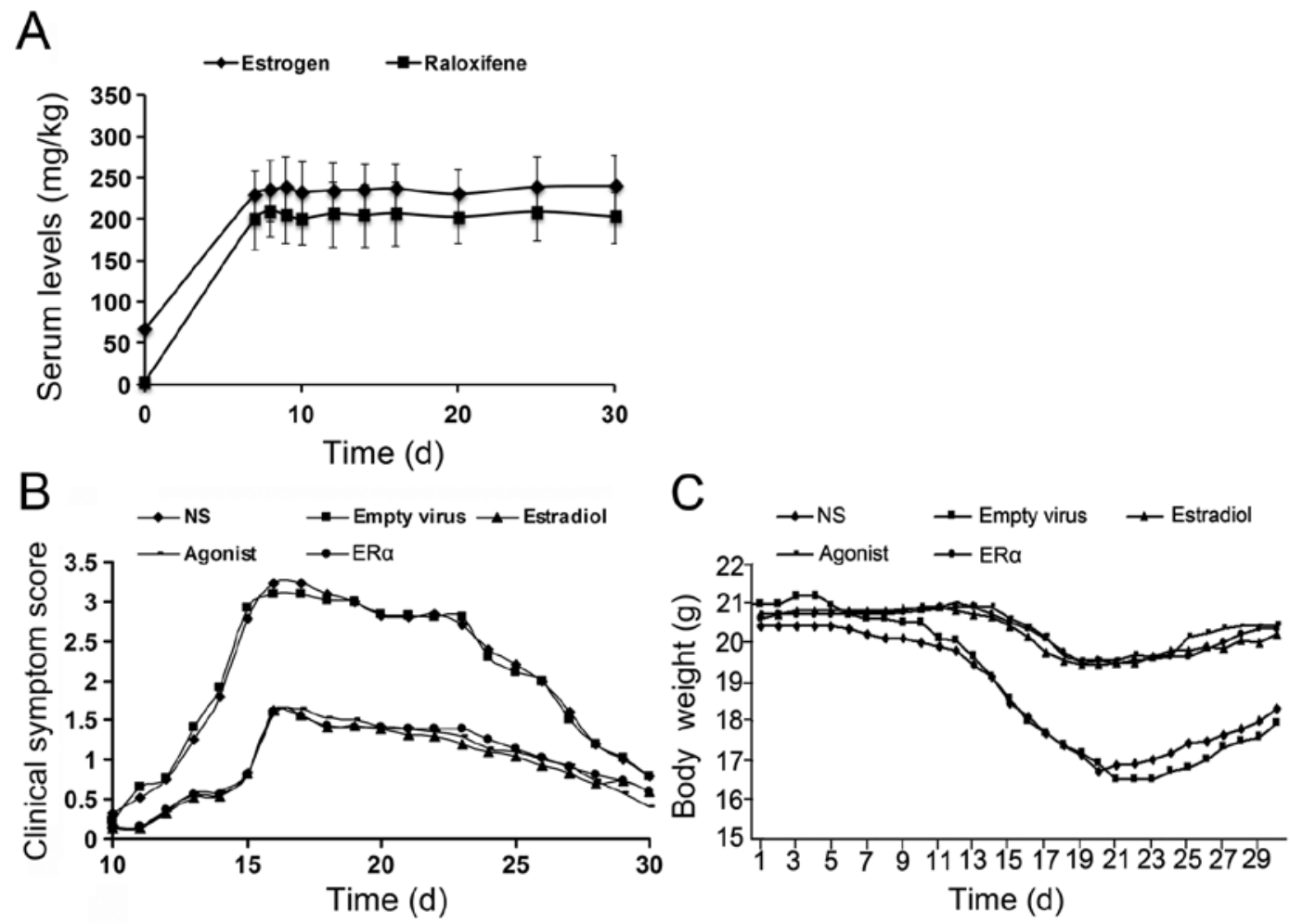

Figure 2. Disease symptom scores and body weight curves of encephalomyelitis (EAE) mice in each group. (A) Estrogen and raloxifene serum levels over a periof of 30 days. (B) Clinical score curves of EAE mice in each group 1-30 days post-immunization. (C) Body weight curves of EAE mice in each group 1-30 days post-immunization. ER $\alpha$, estrogen receptor $\alpha$; d, days.

relevant serum therapeutic levels. Baseline measurements were made at day 0 . The graph in Fig. 2A shows that the treatment successfully increased the serum levels of estrogen and raloxifene over a period of 30 days.

Mice that received recombinant ER $\alpha$ lentivirus were used to assess the possible protective role of ER $\alpha$ against the clinical manifestations of EAE (Fig. 2B). In the empty virus and NS group, symptoms appeared on approximately the 12th day post-immunization, including decreased physical activity, loss of appetite and body weight and tail and limb paralysis. The most severe symptoms manifested on the 14-18th day post-immunization (peaking on day 16, acute stage) and gradually improved from day 23 on (remission stage). After 30 days, the mice had fully recovered, but mild neurological dysfunction was detected in some animals (chronic phase). The total incidence rate of EAE was $>90 \%$ in the empty virus and NS group; the maximum weight loss was $4.183 \pm 1.358$ and $4.3 \pm 1.226 \mathrm{~g}$, and the maximum clinical scores were $3.23 \pm 0.831$ and 3.09 \pm 0.834 , respectively (Fig. $2 \mathrm{~B}$ and C). Compared to the empty virus and NS group, ER $\alpha$ overexpression significantly improved EAE symptoms throughout the entire observation period, including delayed disease onset (symptoms appeared on the 14th day post-immunization), low EAE incidence rate (14.29\%) and evident symptom relief (Fig. 2B), similar to the estrogen and $\mathrm{ER} \alpha$ agonist group. In the estrogen, $\mathrm{ER} \alpha$ agonist and $\mathrm{ER} \alpha$ recombinant lentivirus group, the maximum weight loss was $1.244 \pm 0.554,1.172 \pm 0.63$ and $1.341 \pm 0.481 \mathrm{~g}$, and the maximum clinical scores were $1.62 \pm 1.082,1.57 \pm 1.117$ and $1.61 \pm 1.135$, respectively, which were all significantly lower than those in the empty virus or NS group ( $\mathrm{P}<0.05$, Fig. $2 \mathrm{~B}$ and $\mathrm{C}$ ). At day 30 post-immunization, observation of the ovarian and uterine tissues of mice in each group revealed a single EAE mouse with endometrial thickening in the estrogen group, but similar findings were not observed in the other groups.

ER $\alpha$ overexpression inhibits inflammatory cell infiltration and nerve fiber demyelination in EAE mice. Since the most significant features of EAE are inflammatory cell invasion and nerve fiber demyelination, we investigated the effect of ER $\alpha$ overexpression on both these parameters. We observed significant inflammatory cell infiltration, mainly lymphocytes, into the spinal cord during acute EAE in the empty virus and NS group (Fig. 3D and E). This was dramatically attenuated by ER $\alpha$ overexpression and the administration of estrogen or ER $\alpha$ agonist (Fig. 3A-C and F, P<0.001). Similarly, significant demyelination was observed in the empty virus and NS group, which also improved following treatment with $\mathrm{ER} \alpha$ recombinant lentivirus and estrogen or ER $\alpha$ agonist (Fig. 3G-L).

ER $\alpha$ overexpression increases MBP expression. MBP is a membrane protein that is specifically expressed in myelin-forming cells (33). Mice with a reduced MBP expression exhibit serious nerve fiber myelination defects in the CNS $(33,34)$, suggesting that MBP plays an important role in myelin formation. To further confirm that ER $\alpha$ overexpression inhibits nerve fiber demyelination in EAE mice, MBP expression was analyzed by immunohistochemistry. We found that MBP protein levels were significantly increased in the brain 

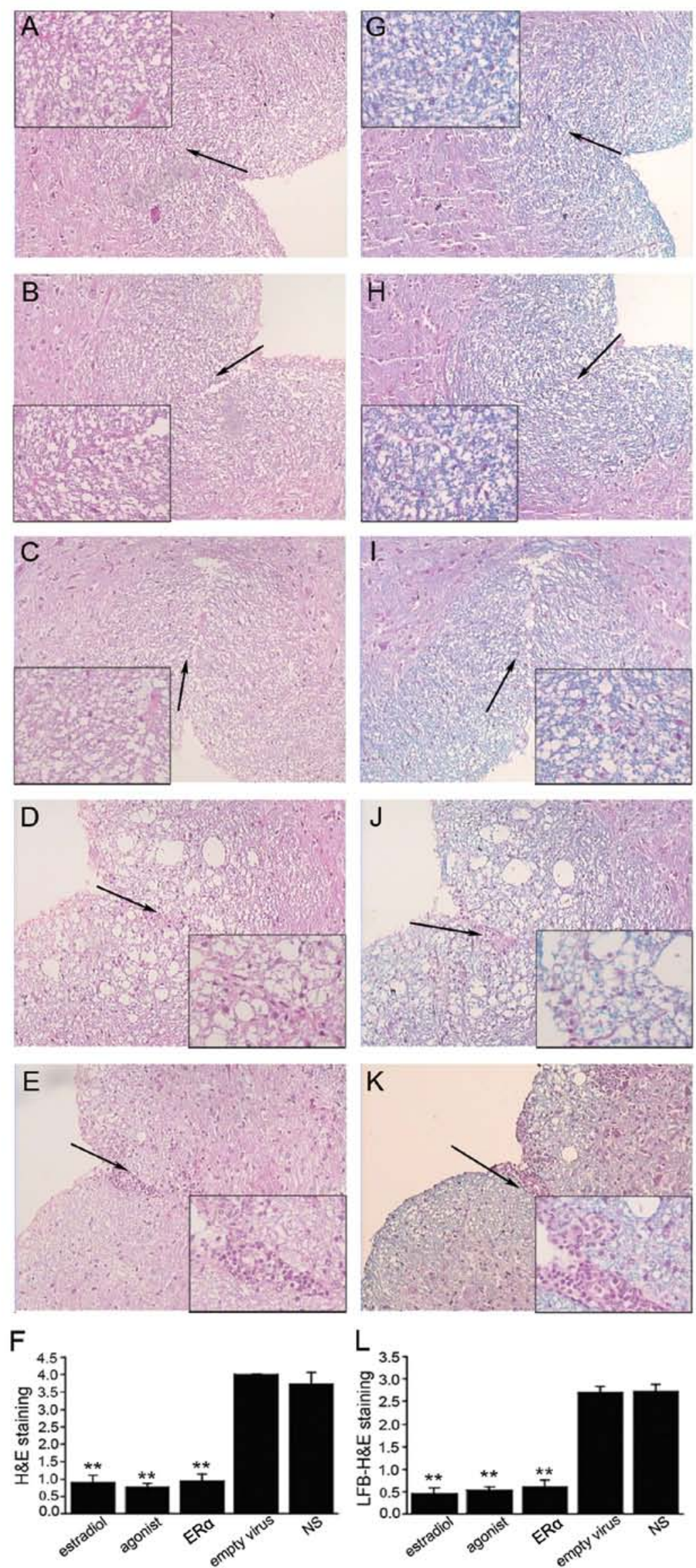

Figure 3. Histological analysis of inflammation and demyelination. (A-E) H\&E staining; (G-K) LFB-H\&E staining; (A and G) estrogen group; (B and H) estrogen receptor (ER) $\alpha$ agonist group; (C and I) ER $\alpha$ group; (D and J) empty vector group; (E and K) normal saline (NS) group (x40); (F) inflammatory cell infiltration quantification (H\&E staining, A-E), $n=5,{ }^{* *} \mathrm{P}<0.001$ compared to the empty vector group; (L) demyelination quantification (LFB-H\&E staining, H-L), $\mathrm{n}=5$, ${ }^{* * *} \mathrm{P}<0.001$ compared to the empty vector group. 

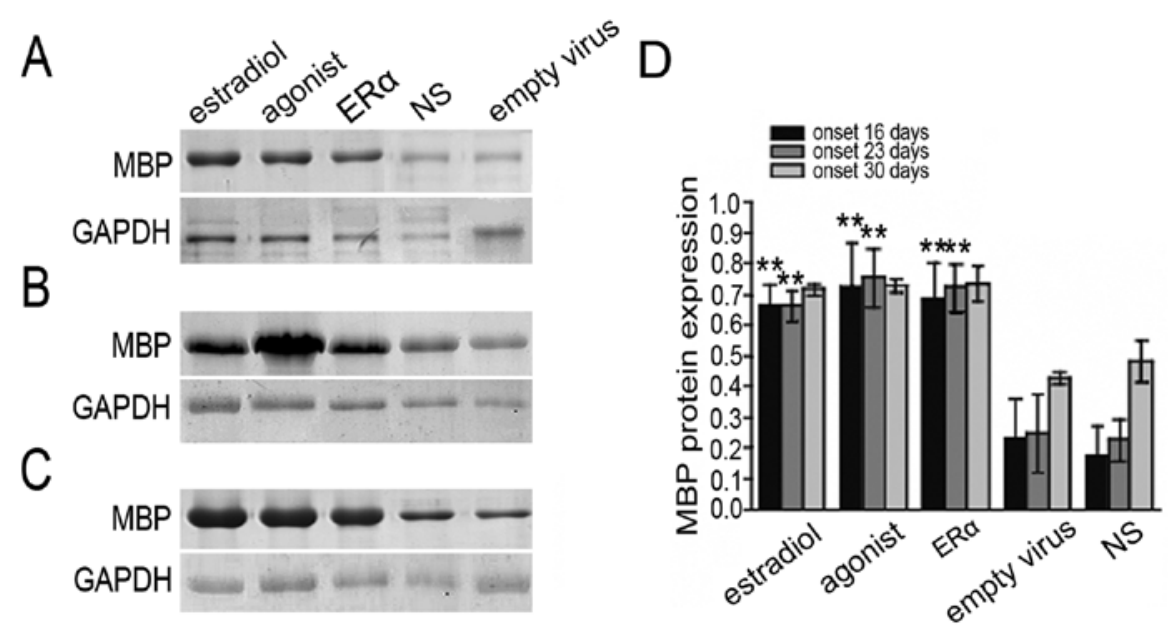

Figure 4. Myelin basic protein (MBP) protein expression in encephalomyelitis (EAE) mice. (A-C) Western blot analysis detection of MBP in EAE mouse brains during the acute (16 days post-immunization, A), remission (23 days post-immunization, B) and chronic phases (30 day post-immunization, C). (D) MBP protein expression densitometry, $\mathrm{n}=5,{ }^{*} \mathrm{P}<0.05$ and ${ }^{* *} \mathrm{P}<0.001$ compared to the empty vector group at the same time point.

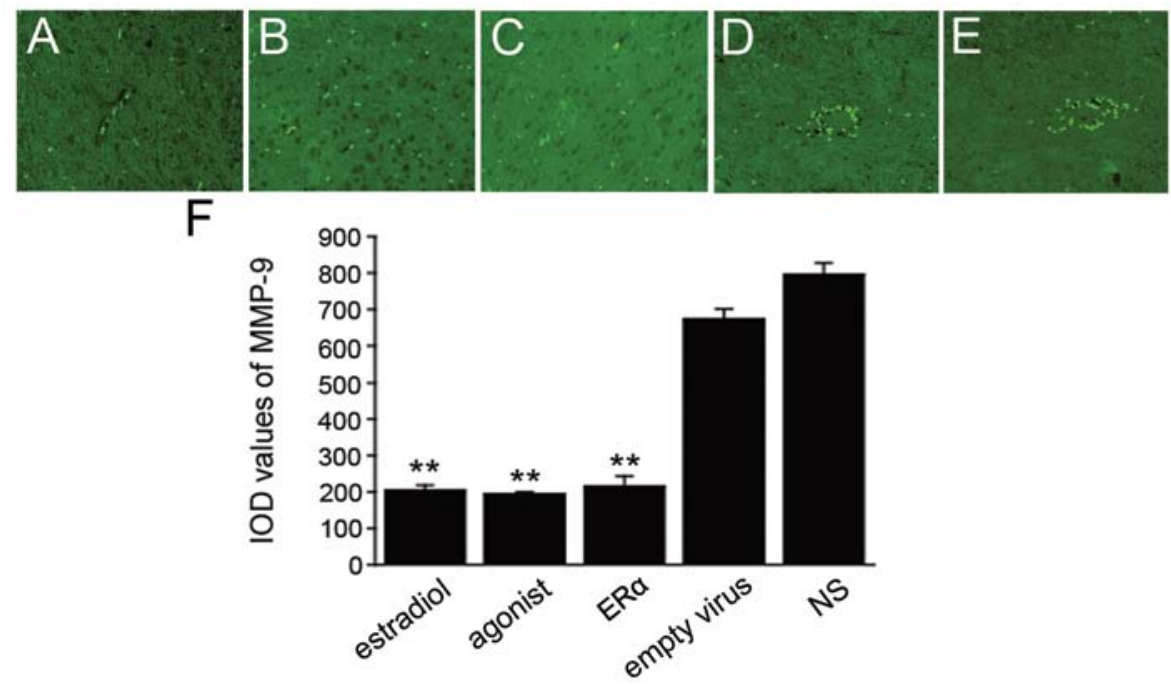

Figure 5. Immunohistochemical analysis of matrix metalloproteinase-9 (MMP-9) expression in encephalomyelitis (EAE) mouse spinal cord. (A) Estrogen group; (B) estrogen receptor (ER) $\alpha$ agonist group; (C) ER $\alpha$ group; (D) empty virus group; (E) normal saline (NS) group (x200); (F) Comparison of the MMP-9 integral optical density (IOD) values in samples from each group, $n=5,{ }^{* *} \mathrm{P}<0.001$ compared to the empty vector group.

in the ER $\alpha$, estradiol, and raloxifene groups (Fig. 4). These results indicate that $\mathrm{ER} \alpha$ overexpression has a similar effect to estrogen therapy on demyelination in EAE mice.

ER $\alpha$ overexpression inhibits MMP-9 expression. The expression of the proteolytic enzyme, MMP-9, is increased in EAE models and results in blood-brain barrier damage and a series of demyelinating events $(35,36)$. We investigated MMP-9 expression following the induction of ER $\alpha$ overexpression in an EAE mouse model and investigated the mechanism behind the antiinflammatory effects exerted by ER $\alpha$. We observed extensive infiltration of MMP-9-positive cells into the spinal cord in the NS and empty virus group. These cells, which typically present green cytoplasmic fluorescence, formed infiltration lesions around small blood vessels (Fig. 5D and E). Although MMP-9positive cell infiltration into the spinal cord was also evident in the ER $\alpha$, estrogen and ER $\alpha$ agonist group, the numbers of MMP-9-positive cells were significantly decreased (Fig. 5A-C) compared to the empty virus group, as evidenced by the significantly lower IOD values (Fig. 5F, P<0.001). These results suggest that the inhibition of MMP-9 expression by ER $\alpha$ overexpression may be one of the possible protective mechanisms against EAE symptoms in mice.

ER $\alpha$ overexpression decreases inflammatory cytokine expression levels in EAE mice. It is known that the expression of inflammatory cytokines, such as TNF- $\alpha$, IFN- $\gamma$, IL-4, IL-17 and IL-23 is usually increased in EAE. To further examine the correlation between inflammation and protection against EAE by ER $\alpha$ overexpression, we measured the levels of inflammatory cytokines, including TNF- $\alpha$, IFN- $\gamma$, IL-4, IL-17 and IL-23. We found that the levels of MMP-9, TNF- $\alpha$, IFN- $\gamma$, IL-17, IL-23 and IL-17 in the EAE mouse brains were downregulated after the body weight recovery and disease symptoms remittance, while IL-4 levels were increased. Compared to the empty virus and NS group, ER $\alpha$ overexpression or treatment with estrogen or 
A

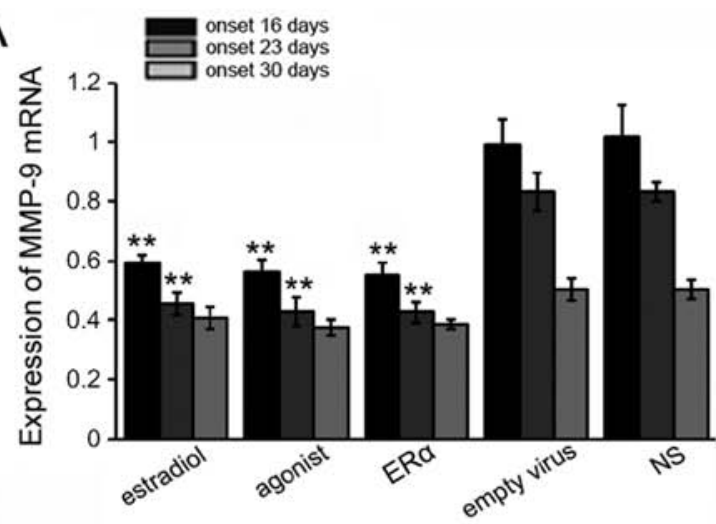

C

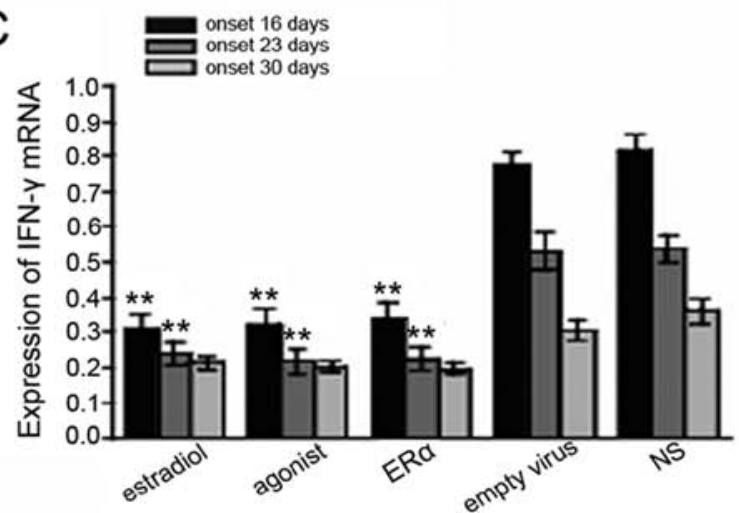

E

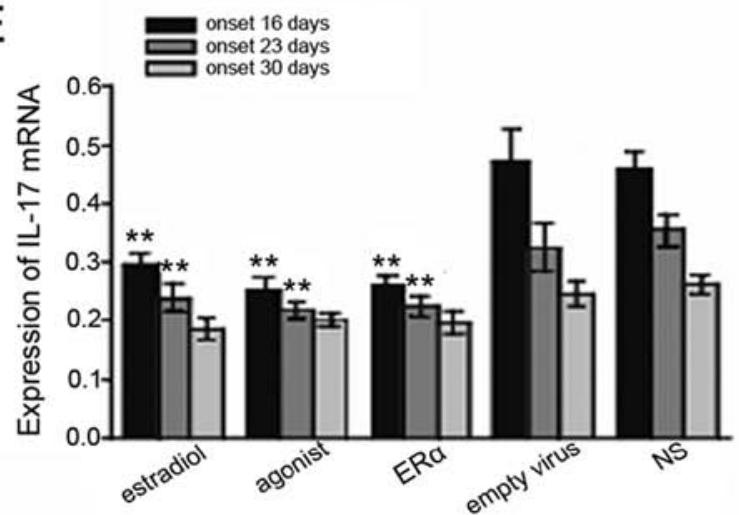

B

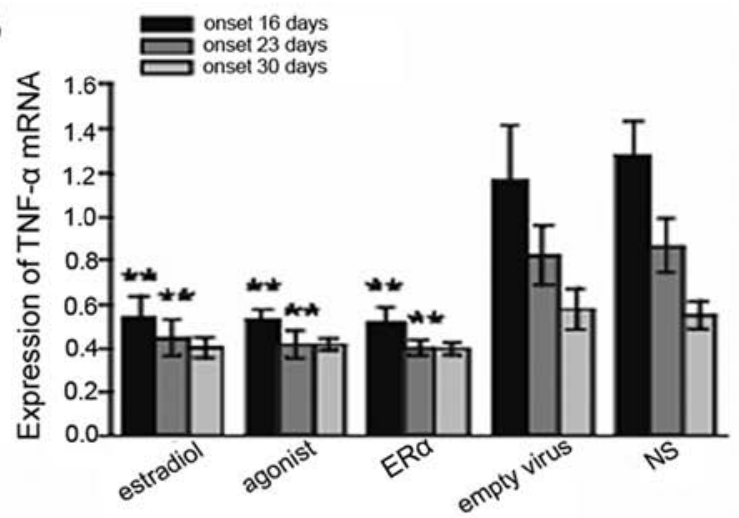

D

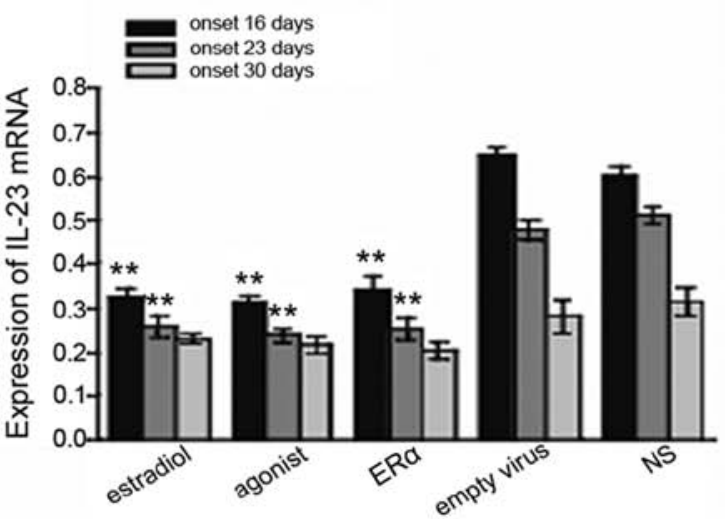

F

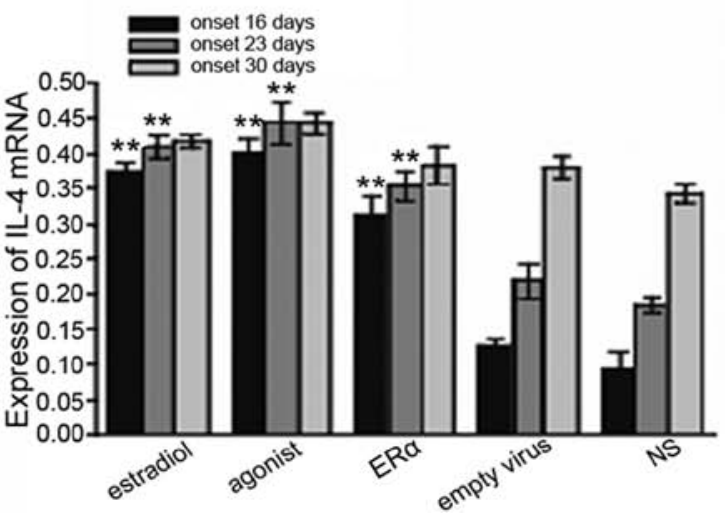

Figure 6. Inflammatory cytokine mRNA expression levels in encephalomyelitis (EAE) mouse brain tissues. RT-PCR was performed to analyze inflammatory cytokine mRNA expression in brain tissues. (A) Matrix metalloproteinase-9 MMP-9; (B) tumor necrosis factor (TNF)- $\alpha$; (C) interferon (IFN)- $\gamma$; (D) interleukin (IL)-23; (E) IL-17; (F) IL-4; $n=5 ;{ }^{* *} \mathrm{P}<0.001$ compared to the empty vector group at the same time point ER, estrogen receptor; NS, normal saline.

ER $\alpha$ agonist significantly decreased the levels of inflammatory cytokines in the EAE mice, but increased those of IL-4 (Figs. 6 and 7). Taken together, our results suggest that the protective effects against EAE by lentiviral-mediated ER $\alpha$ overexpression may occur through inflammatory response inhibition.

\section{Discussion}

A number of studies have demonstrated that estrogen or ER $\alpha$ agonists are beneficial for MS $(5,12,20)$. The main aim of the present study was to investigate the feasibility of lentivirus-mediated overexpression of ER $\alpha$ in the CNS in EAE and to elucidate the mechanisms underlying its effects. ER $\alpha$ overexpression resulted in significant symptom improvement and successfully inhibited inflammatory cytokines in EAE mice. We introduced the recombinant lentivirus vectors via the administration of lateral cerebral ventricle injections. Compared to adenovirus, lentivirus has high transfection efficiency in non-dividing cells, a sustained expression potency and minimal impact on normal cellular functions (37-39). Previous studies have demonstrated the feasibility of the lentivirus-mediated delivery of $\operatorname{ER} \alpha(26,40)$. These studies suggest that lentivirus may have great potential for clinical gene therapy, particularly for manipulating CNS gene expression (41). To date, to our knowledge, there are no reports of the use of recombinant lentivirus overexpressing ER $\alpha$ in EAE mouse models; the majority of studies have employed $\mathrm{ER} \alpha$ ligands or selective ER agonists. The results described in this study illustrate that recombinant lentivirus increases ER $\alpha$ 
A

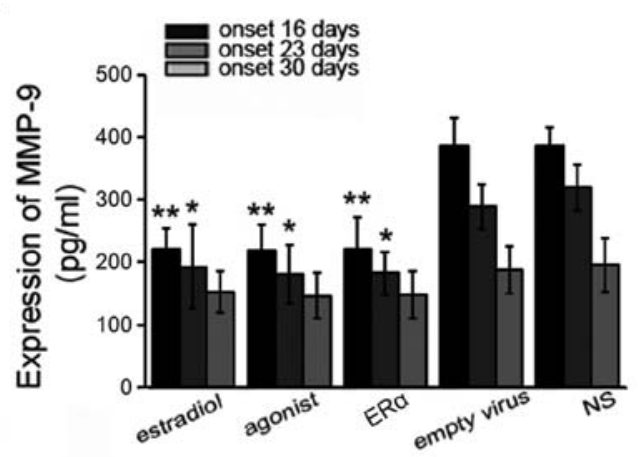

C

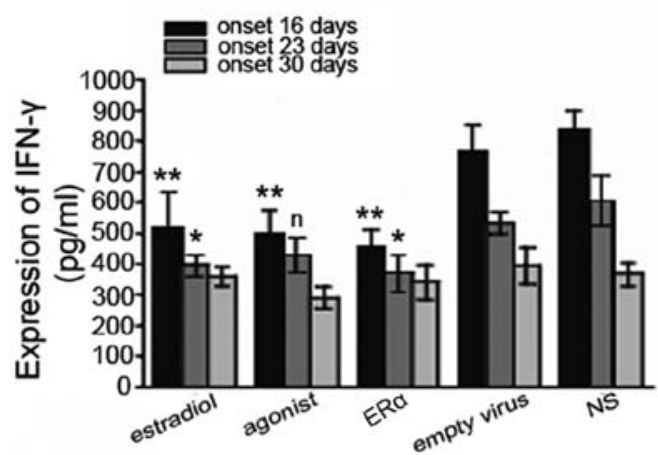

E

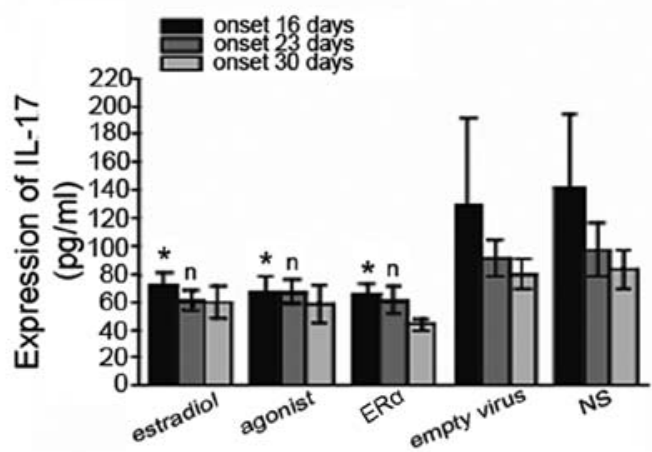

B

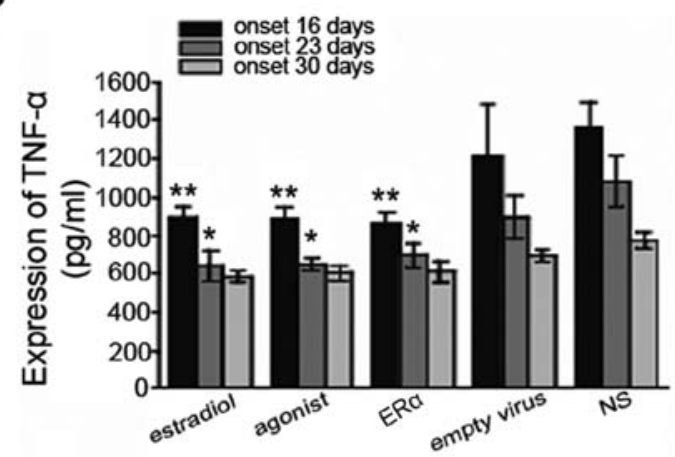

D

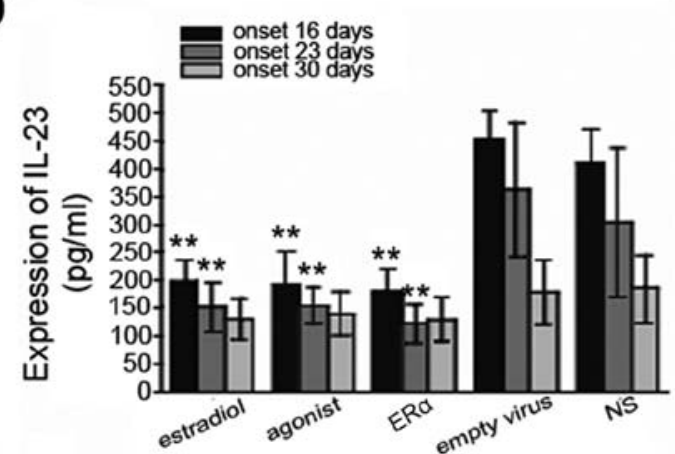

F

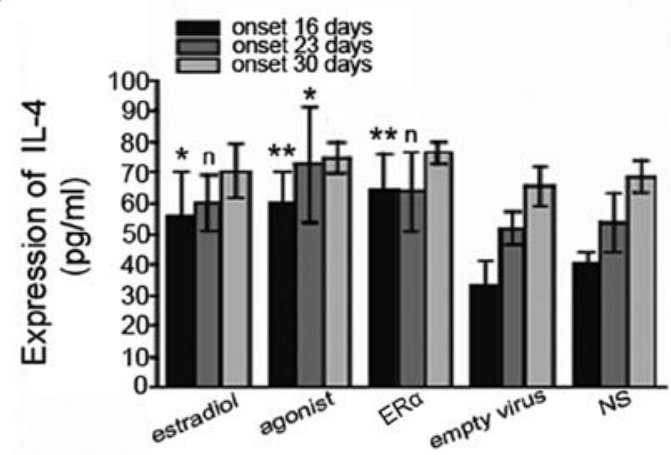

Figure 7. Inflammatory cytokine concentrations in encephalomyelitis (EAE) mouse brain tissue. ELISA were used to determine inflammatory cytokine concentrations in brain tissue. (A) Matrix metalloproteinase-9 MMP-9; (B) tumor necrosis factor (TNF)- $\alpha$; (C) interferon (IFN)- $\gamma$; (D) interleukin (IL)-23; (E) IL-17; (F) IL-4; $n=5 ;{ }^{* *} \mathrm{P}<0.001,{ }^{*} \mathrm{P}<0.05$, compared to the empty vector group at the same time point; n, no significance compared with the empty vector group at the same time point ER, estrogen receptor; NS, normal saline.

expression at the gene and protein level and provide additional evidence for the crucial role of $\mathrm{ER} \alpha$ in EAE.

MS is an autoimmune disease characterized by increased CNS inflammation and demyelination (42). Liu et al reported that estrogen decreased TNF- $\alpha$, IFN- $\gamma$ and IL-12 production in mature DCs. In addition, MBP-specific T cells co-cultured with estrogen-pretreated mature DCs in the presence of antigen demonstrated a shift towards the production of $\mathrm{Th} 2$ cytokines, IL-4 and IL-10, and a concomitant decrease in the production of Th1 cytokines, TNF- $\alpha$ and IFN- $\gamma$ (43). In the present study, clear demyelination and inflammatory cell infiltration were observed in the CNS of EAE mice, and both were attenuated by $\mathrm{ER} \alpha$ overexpression. LFB-H\&E staining showed that demyelinated regions contained a high number of inflammatory cells, suggesting that demyelination may be closely associated with the activation of inflammation, and that $\mathrm{ER} \alpha$ overexpression attenuates the inflammatory response. Previous studies have suggested that changes in oligodendrocyte markers can yield valuable information on demyelination-associated diseases $(44,45)$, and MBP appears to be the most relevant. This abundant protein is believed to stabilize myelin sheaths (46), and demyelinated MS lesions and nearby areas have a reduced or absent MBP expression $(47,48)$. Levels of MBP (both mRNA and protein) have been associated with de- and remyelination processes in other neurological disorders, and it is considered a specific and sensitive index for measuring oligodendrocyte injury and demyelination. MBP loss is known to precede the onset of myelin histological changes (49). In this study, western blot analysis and RT-PCR revealed that MBP expression was significantly reduced at the initial stage of EAE, and myelin sheath damage was gradually alleviated during the remission stage, indicating that myelin sheath damage is closely associated with EAE development.

We observed significant increases in MBP expression in the groups treated with $\mathrm{ER} \alpha$ recombinant lentivirus and 
estrogen, which also exhibited reduced myelin loss during EAE. Therefore, the ER $\alpha$-mediated attenuation of demyelination may at least partly be due to MBP upregulation. Crawford et al reported that ER $\beta$ ligand treatment exerted direct neuroprotective effects on oligodendrocyte differentiation, myelination and axon conduction following EAE (50). However, these results are time-dependent; early treatment can reduce the inflammatory response and myelin sheath damage, but late treatment is ineffective (19). Therefore, early intervention for EAE and MS is critical.

Although it is well established that a subcutaneous injection of estrogen or ER agonist protects against neurodegenerative and CNS immune diseases (51-53), long-term use may increase the risk of breast cancer and cardiovascular disease (54). Conversely, the lentiviral manipulation of CNS ER $\alpha$ expression can mimic the therapeutic effect of estrogen, while avoiding unwanted side-effects. In this study, we pathologically analyzed the ovarian and uterine tissues of EAE mice in various groups during the experimental period and found a single mouse with mild endometrial thickening in the estrogen group, but similar changes were not observed in the other groups. However, these animals were only treated acutely, and further studies are required to validate the safety and clinical feasibility of ER $\alpha$ recombinant lentivirus.

Th1/Th2 balance is crucial for immune defense and surveillance. MS patients usually show an imbalance in Th1/ Th2 cytokine expression (55-57), and addressing Th1/Th2 expression levels has become a novel therapeutic strategy for MS patients (58). Bebo et al found that selective estrogenreceptor modulators (SERMs) caused a Th2 shift by decreasing IFN- $\gamma$ - and TNF- $\alpha$-producing $\mathrm{CD}^{+}{ }^{+} \mathrm{T}$ cells and increasing IL-4-producing $\mathrm{CD}^{+} \mathrm{T}$ cells. These results suggest that SERMs may potentially be used to treat inflammatory autoimmune disorders that affect the CNS (59). In this study, we found that TNF- $\alpha$ and IFN- $\gamma$ expression was significantly increased in the EAE mice, particularly in the acute stage of the disease, and the level of Th1 cytokines gradually decreased as the clinical symptoms remitted. In addition, Th1 cytokine expression (TNF- $\alpha$ and IFN- $\gamma$ ) was decreased following the induction of ER $\alpha$ overexpression and treatment with estrogen or ER agonist. IFN $-\gamma$ promotes the differentiation of Th0 cells to Th1 cells and stimulates the release of lymphotoxin, IL-1 and TNF- $\alpha$, resulting in demyelination and EAE development $(60,61)$. In addition, EAE is also closely related to the expression of the zinc calcium-dependent protease, MMP-9, which is expressed in Th1 cells and increases their migration (62), allowing immune cells to access the CNS during the the early stages of MS. Abnormal MMP-9 expression and increased activation in EAE mice can impair the blood-brain barrier and allow myelin degradation $(35,36)$. Gold et al reported that estriol acts through ER $\alpha$ to reduce immune cell-mediated MMP-9 production, which is one of the potential mechanisms by which estriol reduces MS and EAE inflammatory lesions (23). Increased MMP-9 serum levels have also been observed in patients with clinically isolated syndrome (CIS), and MMP-9 levels further increase in patients who go on to develop MS compared to CIS patients who do not convert (63). We found that MMP-9 was downregulated following the induction of ER $\alpha$ overexpression and treatment with estrogen or ER agonist. We postulate that all 3 treatments decreased Th1 cytokine production and reduced the differentiation of Th0 cells to Th1 cells. Conversely, the expression of IL-4, which is released by Th2 cells, was increased. As a result, the regulation of pro- or anti-inflammatory cytokines by $\mathrm{ER} \alpha$ overexpression suggests that the therapeutic effect of ER $\alpha$ on EAE may be due to restoring Th1/Th2 balance. This is similar to what has been reported previously; however, our experimental design was more rigorous and included multiple time points. Our results indicate that $\mathrm{ER} \alpha$ recombinant lentivirus can control the Th1/ Th2 cytokine imbalance at the acute stage of EAE in mice. This novel finding demonstrates the effectiveness and possibility of using ER $\alpha$ recombinant lentivirus for the treatment of EAE and MS.

We also demonstrated the effects of ER $\alpha$ overexpression, estradiol and raloxifene on the IL-23/IL-17 axis throughout EAE progression. The IL-23/IL-17 axis has been suggested to play an important role in MS pathogenesis (64). IL-23 induces the production of inflammatory cytokines, such as IL-16, IL-17, IL-17F and TNF- $\alpha$ (65). IL-17 stimulates various inflammatory cytokines, including IL-1, IL-6, TNF- $\alpha$, nitric oxide synthase, MMPs and chemical factors $(66,67)$. EAE severity is reportedly associated with serum IL-17 levels (68), and an injection of anti-IL-17 antibody has been shown to reduce the incidence of autoimmune diseases and inflammation severity (69). Estrogeninduced EAE protection is mediated by upregulated PD-1 expression within the Treg-cell compartment, which reduces peripheral IL-17 production (9). Lelu et al demonstrated that hematopoietic cell ER $\alpha$ expression is critical for mediating E2s inhibitory effect on Th1 and Th17 cell priming, which results in EAE protection (8). However, to our knowledge, there have been no publications regarding the effect of ER $\alpha$ on IL-23 in EAE. In our study, we observed that both IL-23 and IL-17 were downregulated following the induction of $\mathrm{ER} \alpha$ overexpression, as well as following the oral supplementation of estrogen or ER agonist in EAE mice, suggesting that modulating the IL-23/ IL-17 axis by overexpressing ER $\alpha$ may contribute to its protective effect against EAE.

In conclusion, the present study indicates that CNS ER $\alpha$ overexpression with lentivirus attenuates EAE symptoms via multiple mechanisms, including the suppression of inflammation and reduced demyelination. Additionally, appropriate balances of inflammatory cytokines in the Th1/Th2 and IL-23/ IL-17 axes may also contribute to the observed therapeutic effects of ER $\alpha$ overexpression. These results provide evidence for the utility of manipulating ER $\alpha$ expression in the CNS with lentivirus delivery. Further studies are required to elucidate the effects of ER $\alpha$ overexpression in EAE and MS.

\section{Acknowledgements}

This study was supported by a grant from the Research Project of Science and Technology, Department of Guizhou Province, No. sy[2009]3054 and the Special Fund of the Governor of Guizhou Province for Excellent Scientific, Technological and Educational Talents, No. Qian Sheng Zhuan He Zi (2010) 86. We would like to thank the Central Laboratory and Molecular Biochemical Laboratory of Guizhou Provincial People's Hospital for the excellent experimental environment and Anzhi Wen from the Pathological Laboratory of Guizhou Provincial People's Hospital for providing technical support. 


\section{References}

1. Ouallet J, Baumann N, Marie Y and Villarroya H: Fas system up-regulation in experimental autoimmune encephalomyelitis. J Neurol Sci 170: 96-104, 1999.

2. Barac-Latas V, Muhvic D and Radosevic-Stabic B: The influence of pregnancy on development and course of chronic relapsing experimental autoimmune encephalomyelitis in rats: implications for multiple sclerosis. Coll Antropol 34 (Suppl 1): 267-271, 2010.

3. Runmarker B and Andersen O: Pregnancy is associated with a lower risk of onset and a better prognosis in multiple sclerosis Brain 118: 253-261, 1995

4. Confavreux C, Hutchinson M,Hours MM, Cortinovis-Tourniaire P and Moreau T: Rate of pregnancy-related relapse in multiple sclerosis. Pregnancy in Multiple Sclerosis Group. N Engl J Med 339: 285-291, 1998.

5. Niino M, Hirotani M, Fukazawa T, Kikuchi $\mathrm{S}$ and Sasaki $\mathrm{H}$ : Estrogens as potential therapeutic agents in multiple sclerosis Cent Nerv Syst Agents Med Chem 9: 87-94, 2009.

6. Sicotte NL, Liva SM, Klutch R, et al: Treatment of multiple sclerosis with the pregnancy hormone estriol. Ann Neurol 52 421-428, 2002.

7. Soldan SS, Alvarez Retuerto AI, Sicotte NL and Voskuhl RR: Immune modulation in multiple sclerosis patients treated with the pregnancy hormone estriol. J Immunol 171: 6267-6274, 2003

8. Lelu K, Laffont S, Delpy L, et al: Estrogen receptor alpha signaling in T lymphocytes is required for estradiol-mediated inhibition of Th1 and Th17 cell differentiation and protection against experimental autoimmune encephalomyelitis. J Immunol 187: 2386-2393, 2011.

9. Wang C, Dehghani B, Li Y, et al: Membrane estrogen receptor regulates experimental autoimmune encephalomyelitis through up-regulation of programmed death 1. J Immunol 182: 3294-3303, 2009.

10. Bodhankar S, Wang C, Vandenbark AA and Offner H: Estrogeninduced protection against experimental autoimmune encephalomyelitis is abrogated in the absence of B cells. Eur J Immunol 41: $1165-1175,2011$

11. Subramanian S, Yates M, Vandenbark AA and Offner $H$ : Oestrogen-mediated protection of experimental autoimmune encephalomyelitis in the absence of Foxp $3^{+}$regulatory T cells implicates compensatory pathways including regulatory B cells. Immunology 132: 340-347, 2011.

12. Gold SM and Voskuhl RR: Estrogen treatment in multiple sclerosis J Neurol Sci 286: 99-103, 2009.

13. MacKenzie-Graham AJ, Rinek GA, Avedisian A, et al: Estrogen treatment prevents gray matter atrophy in experimental autoimmune encephalomyelitis. J Neurosci Res 90: 1310-1323, 2012.

14. Ziehn MO, Avedisian AA, Dervin SM, O'Dell TJ and Voskuhl RR Estriol preserves synaptic transmission in the hippocampus during autoimmune demyelinating disease. Lab Invest 92: 1234-1245, 2012.

15. Giraud SN, Caron CM, Pham-Dinh D, Kitabgi P and Nicot AB: Estradiol inhibits ongoing autoimmune neuroinflammation and NFkappaB-dependent CCL2 expression in reactive astrocytes. Proc Natl Acad Sci USA 107: 8416-8421, 2010.

16. Bodhankar S and Offner $\mathrm{H}$ : Gpr30 forms an integral part of E2-protective pathway in experimental autoimmune encephalomyelitis. Immunol Endocr Metab Agents Med Chem 11: 262-274, 2011

17. Matejuk A, Bakke AC, Hopke C, Dwyer J, Vandenbark AA and Offner H: Estrogen treatment induces a novel population of regulatory cells, which suppresses experimental autoimmune encephalomyelitis. J Neurosci Res 77: 119-126, 2004.

18. Tiwari-Woodruff S and Voskuhl RR: Neuroprotective and antiinflammatory effects of estrogen receptor ligand treatment in mice. J Neurol Sci 286: 81-85, 2009.

19. Du S, Sandoval F, Trinh P, Umeda E and Voskuhl R: Estrogen receptor-beta ligand treatment modulates dendritic cells in the target organ during autoimmune demyelinating disease. Eur J Immunol 41: 140-150, 2011.

20. Blasko E, Haskell CA, Leung S, et al: Beneficial role of the GPR30 agonist G-1 in an animal model of multiple sclerosis. J Neuroimmunol 214: 67-77, 2009.

21. Subramanian S, Miller LM, Grafe MR, Vandenbark AA and Offner H: Contribution of GPR30 for 1,25 dihydroxyvitamin $\mathrm{D}(3)$ protection in EAE. Metab Brain Dis 27: 29-35, 2012.

22. Lelu K, Delpy L, Robert V, et al: Endogenous estrogens, through estrogen receptor alpha, constrain autoimmune inflammation in female mice by limiting CD4 ${ }^{+}$T-cell homing into the CNS. Eur J Immunol 40: 3489-3498, 2010
23. Gold SM, Sasidhar MV, Morales LB, et al: Estrogen treatment decreases matrix metalloproteinase (MMP)-9 in autoimmune demyelinating disease through estrogen receptor alpha (ERalpha). Lab Invest 89: 1076-1083, 2009.

24. Spence RD, Hamby ME, Umeda E, et al: Neuroprotection mediated through estrogen receptor-alpha in astrocytes. Proc Natl Acad Sci USA 108: 8867-8872, 2011.

25. Wong LF, Goodhead L, Prat C, Mitrophanous KA, Kingsman SM and Mazarakis ND: Lentivirus-mediated gene transfer to the central nervous system: therapeutic and research applications. Hum Gene Ther 17: 1-9, 2006.

26. Foster TC, Rani A, Kumar A, Cui L and Semple-Rowland SL: Viral vector-mediated delivery of estrogen receptor-alpha to the hippocampus improves spatial learning in estrogen receptoralpha knockout mice. Mol Ther 16: 1587-1593, 2008.

27. Brewer GJ, Torricelli JR, Evege EK and Price PJ: Optimized survival of hippocampal neurons in B27-supplemented Neurobasal, a new serum-free medium combination. J Neurol Sci 35: 567-576, 1993.

28. Hu X, Lei L, Yuan J, Xing W, W JY and Qin X: Construction of recombinant lentivirus carrying mouse estrogen receptor $\alpha$ and identification in infected neurons. Acad J Sec Mil Med Univ 32: 160-166, 2011.

29. Tiwari-Woodruff S, Morales LB, Lee R and Voskuhl RR: Differential neuroprotective and antiinflammatory effects of estrogen receptor (ER)alpha and ERbeta ligand treatment. Proc Natl Acad Sci USA 104: 14813-14818, 2007.

30. Tapia-Gonzalez S, Carrero P, Pernia O, Garcia-Segura LM and Diz-Chaves Y: Selective Er modulators reduce microglia reactivity in vivo after peripheral inflammation: potential role of microglial ERs. J Endocrinol 198: 219-230, 2008.

31. Legge KL, Min B, Bell JJ, et al: Coupling of peripheral tolerance to endogenous interleukin 10 promotes effective modulation of myelin-activated $\mathrm{T}$ cells and ameliorates experimental allergic encephalomyelitis. J Exp Med 191: 2039-2052, 2000.

32. Murphy AC, Lalor SJ, Lynch MA and Mills KH: Infiltration of Th1 and Th17 cells and activation of microglia in the CNS during the course of experimental autoimmune encephalomyelitis. Brain Behav Immun 24: 641-651, 2010.

33. Jacobs EC: Genetic alterations in the mouse myelin basic proteins result in a range of dysmyelinating disorders. J Neurol Sci 228 195-197, 2005.

34. Molineaux SM, Engh H, De Ferra F, Hudson L and Lazzarini RA: Recombination within the myelin basic protein gene created the dysmyelinating shiverer mouse mutation. Proc Natl Acad Sci USA 83: 7542-7546, 1986.

35. Fainardi E, Castellazzi M, Bellini T, et al: Cerebrospinal fluid and serum levels and intrathecal production of active MMP-9 as markers of disease activity in patients with multiple sclerosis. Mult Scler 12: 294-301, 2006.

36. Kurzepa J, Bartosik-Psujek H, Suchozebrska-Jesionek D, Rejdak K, Stryjecka-Zimmer M and Stelmasiak Z: Role of matrix metalloproteinases in the pathogenesis of multiple sclerosis. Neurol Neurochir Pol 39: 63-67, 2005 (In Polish).

37. Rubinson DA, Dillon CP, Kwiatkowski AV, et al: A lentivirusbased system to functionally silence genes in primary mammalian cells, stem cells and transgenic mice by RNA interference. Nat Genet 33: 401-406, 2003.

38. Trobridge G and Russell DW: Cell cycle requirements for transduction by foamy virus vectors compared to those of oncovirus and lentivirus vectors. J Virol 78: 2327-2335, 2004

39. Yip PK, Wong LF, Pattinson D, et al: Lentiviral vector expressing retinoic acid receptor beta2 promotes recovery of function after corticospinal tract injury in the adult rat spinal cord. Hum Mol Genet 15: 3107-3118, 2006.

40. Ambrosino C, Tarallo R, Bamundo A, et al: Identification of a hormone-regulated dynamic nuclear actin network associated with estrogen receptor alpha in human breast cancer cell nuclei. Mol Cell Proteomics 9: 1352-1367, 2010.

41. Vigna E and Naldini L: Lentiviral vectors: excellent tools for experimental gene transfer and promising candidates for gene therapy. J Gene Med 2: 308-316, 2000.

42. Bruck W: The pathology of multiple sclerosis is the result of focal inflammatory demyelination with axonal damage. J Neurol 252 (Suppl 5): v3-v9, 2005

43. Liu HY, Buenafe AC, Matejuk A, et al: Estrogen inhibition of EAE involves effects on dendritic cell function. J Neurol Sci 70: 238-248, 2002.

44. Baumann N and Pham-Dinh D: Biology of oligodendrocyte and myelin in the mammalian central nervous system. Physiol Rev 81: 871-927, 2001 
45. Daigle JL, Hong JH, Chiang CS and McBride WH: The role of tumor necrosis factor signaling pathways in the response of murine brain to irradiation. Cancer Res 61: 8859-8865, 2001.

46. Griffiths I, Klugmann M, Anderson T, et al: Axonal swellings and degeneration in mice lacking the major proteolipid of myelin. Science 280: 1610-1613, 1998.

47. De Rosbo NK and Bernard CC: Multiple sclerosis brain immunoglobulins stimulate myelin basic protein degradation in human myelin: a new cause of demyelination. J Neurochem 53: 513-518, 1989.

48. Einstein ER, Csejtey J, Dalal KB, Adams CW, Bayliss OB and Hallpike JF: Proteolytic activity and basic protein loss in and around multiple sclerosis plaques: combined biochemical and histochemical observations. J Neurochem 19: 653-662, 1972.

49. Harauz G, Ishiyama N, Hill CM, Bates IR, Libich DS and Fares C: Myelin basic protein-diverse conformational states of an intrinsically unstructured protein and its roles in myelin assembly and multiple sclerosis. Micron 35: 503-542, 2004.

50. Crawford DK, Mangiardi M, Song B, et al: Oestrogen receptor beta ligand: a novel treatment to enhance endogenous functional remyelination. Brain 133: 2999-3016, 2010.

51. Garay L, Gonzalez Deniselle MC, Gierman L, et al: Steroid protection in the experimental autoimmune encephalomyelitis model of multiple sclerosis. Neuroimmunomodulation 15: 76-83, 2008.

52. Sarkaki A, Amani R, Badavi M, et al: Pre-treatment effect of different doses of soy isoflavones on spatial learning and memory in an ovariectomized animal model of Alzheimer's disease. Pak J Biol Sci 11: 1114-1119, 2008.

53. Sheldahl LC, Marriott LK, Bryant DM, Shapiro RA and Dorsa DM: Neuroprotective effects of estrogen and selective estrogen receptor modulators begin at the plasma membrane. Minerva Endocrinol 32: 87-94, 2007.

54. Riggs BL and Hartmann LC: Selective estrogen-receptor modulators - mechanisms of action and application to clinical practice. N Engl J Med 348: 618-629, 2003.

55. Chitnis T and Khoury SJ: Cytokine shifts and tolerance in experimental autoimmune encephalomyelitis. Immunol Res 28: 223-239, 2003.

56. McGeachy MJ and Anderton SM: Cytokines in the induction and resolution of experimental autoimmune encephalomyelitis. Cytokine 32: 81-84, 2005.

57. Suryani $\mathrm{S}$ and Sutton I: An interferon-gamma-producing Th1 subset is the major source of IL-17 in experimental autoimmune encephalitis. J Neuroimmunol 183: 96-103, 2007.
58. Butti E, Bergami A, Recchia A, et al: IL4 gene delivery to the CNS recruits regulatory $T$ cells and induces clinical recovery in mouse models of multiple sclerosis. Gene Ther 15: 504-515, 2008.

59. Bebo BF Jr, Dehghani B, Foster S, Kurniawan A, Lopez FJ and Sherman LS: Treatment with selective estrogen receptor modulators regulates myelin specific T-cells and suppresses experimental autoimmune encephalomyelitis. Glia 57: 777-790, 2009.

60. Juedes AE,Hjelmstrom P, Bergman CM, Neild AL and Ruddle NH: Kinetics and cellular origin of cytokines in the central nervous system: insight into mechanisms of myelin oligodendrocyte glycoprotein-induced experimental autoimmune encephalomyelitis. J Immunol 164: 419-426, 2000.

61. Monteiro de Castro G, Eduarda Zanin M, Ventura-Oliveira D, Aparecida Vilella C, Ashimine R and De Lima Zollner R: Th1 and $\mathrm{Th} 2$ cytokine immunomodulation by gangliosides in experimental autoimmune encephalomyelitis. Cytokine 26: 155-163, 2004.

62. Abraham M, Shapiro S, Karni A, Weiner HL and Miller A: Gelatinases (MMP-2 and MMP-9) are preferentially expressed by Th1 vs. Th2 cells. J Neuroimmunol 163: 157-164, 2005.

63. Correale J and Bassani Molinas Mde L: Temporal variations of adhesion molecules and matrix metalloproteinases in the course of MS. J Neuroimmunol 140: 198-209, 2003.

64. Illes Z, Safrany E, Peterfalvi A, et al: 3'UTR C2370A allele of the IL-23 receptor gene is associated with relapsing-remitting multiple sclerosis. Neurosci Lett 431: 36-38, 2008.

65. Harrington LE, Hatton RD, Mangan PR, et al: Interleukin 17producing $\mathrm{CD}^{+}$effector T cells develop via a lineage distinct from the T helper type 1 and 2 lineages. Nat Immunol 6: 1123-1132, 2005.

66. Kawanokuchi J, Shimizu K, Nitta A, et al: Production and functions of IL-17 in microglia. J Neuroimmunol 194: 54-61, 2008.

67. Kolls JK and Linden A: Interleukin-17 family members and inflammation. Immunity 21: 467-476, 2004.

68. Tian AY, Zhang RW, Shi XG and Yu HM: Alteration of T helper cell subsets in the optic nerve of experimental autoimmune encephalomyelitis. Int J Mol Med 25: 869-874, 2010

69. Uyttenhove C, Sommereyns C, Theate I, Michiels T and van Snick J: Anti-IL-17A autovaccination prevents clinical and histological manifestations of experimental autoimmune encephalomyelitis. Ann NY Acad Sci 1110: 330-336, 2007. 